\title{
Citrus oils as chain transfer agents in the cross-metathesis degradation of polybutadiene in block copolymers using Ru-alkylidene catalysts
}

\author{
Araceli Martínez $^{1^{*}}$, Selena Gutiérrez ${ }^{2}$, Mikhail A. Tlenkopatchev ${ }^{1^{*}}$ \\ ${ }^{1}$ Instituto de Investigaciones en Materiales, Universidad Nacional Autónoma de México, México City, México; \\ *Corresponding Author: arampmx@yahoo.com.mx, tma@unam.mx \\ ${ }^{2}$ Centro de Investigaciones Biológicas del Noroeste, CIBNOR, México City, México
}

Received 14 May 2013; revised 15 June 2013; accepted 22 June 2013

Copyright (C) 2013 Araceli Martínez et al. This is an open access article distributed under the Creative Commons Attribution License, which permits unrestricted use, distribution, and reproduction in any medium, provided the original work is properly cited.

\begin{abstract}
The cross-metathesis degradation of poly(styrene-co-butadiene) (styrene, $30 \mathrm{wt} \%)(\mathrm{SB}-1)$ and poly(styrene-co-butadiene) (styrene, $21 \mathrm{wt} \%$ ) (SB2 ) in the presence of essential oils and $d$-limonene as chain transfer agents (CTAs) using Rualkylidene catalysts $\left(\mathrm{PCy}_{3}\right)_{2}(\mathrm{Cl})_{2} \mathrm{Ru}=\mathrm{CHPh}$ (I) and (1,3-diphenyl-4,5-dihydroimidazol-2-ylidene) $\left(\mathrm{PCy}_{3}\right) \mathrm{Cl}_{2} \mathrm{Ru}=\mathrm{CHPh}$ (II) was studied. Terpene-terminated butadiene oligomers and polystyrene blocks were obtained as products of the degradation of SB-1 and SB-2. Catalysts I and II showed high activity in the degradation of SB copolymers to produce the low molecular weight products $\left(M_{n}=276-335 \mathrm{~g} \cdot \mathrm{mol}^{-1}\right)$ and yields ranging from $91 \%-95 \%$. The cross-metathesis degradation of copolymers in organic solvents and in citrus oils (mandarin, orange and lemon oils) proceeded with similar efficiency and resulted in the same molecular weight butadiene oligomers. According to GS/MS (EI) analysis, the main products of the degradation of SB-1 copolymer with $d$-limonene were limonene-terminated oligomers of series $A_{m}(m=1$ - 4).
\end{abstract}

Keywords: Metathesis Degradation; Polybutadiene in Block; Natural Oils; $d$-Limonene; Ru-Alkylidene Catalysts

\section{INTRODUCTION}

Mandarin, lemon and other citrus oils are very attractive terpene based compounds. Terpenes are a class of natural products that typically contain carbon atom units built from isoprene molecules. A wide variety of bio- based structures is synthesized by transformations of isoprene monomer units. For example, pinene, $\beta$-carotene, natural rubber, carvone and steroids such as testosterone, cholesterol and estrogen are set of terpene based compounds. In plants, terpenes are found as a main component of the essential oils, that are used as medicines, spices and perfumes [1]. Commercial polymers of monoterpenes prepared usually by Lewis acid catalyzed polymerization are used in many industrial applications for example, as pressure-sensitive adhesives, hot-melt coatings, packaging gum and additives $[2,3]$. The transformations of terpene based molecules using efficient catalysts are of great interest for the development of new applications for these biomass-derived compounds. In this perspective, metathesis transformations are becoming more attractive as the availability and choice of effective catalysts increased [4-6]. The computational modeling of $\beta$-pinene ring-opening metathesis using Grubbs, Schrock and Fischer type metal carbene revealed that the successful catalysts for metathesis of terpene based molecules should have small substituent at a metal active center and a carbon carbene atom. Thus, the lowest activation and reaction energies were found for methylene metalcarbenes [7]. Metathesis transformations of several terpenoids such as citronellal, citronellol and citral using the Ru-alkylidene catalysts have been reported [8-10]. Monoterpenes such as $d$-limonene and $\beta$-pinene have been used in the cross-metathesis reactions with cycloolefins [11-13] and natural rubber [14,15]. The intramolecular and intermolecular metathesis degradation reactions of alternating, random and block copolymers of butadiene and isoprene have been studied [16-23]. Thus, it was reported that the cyclodegradation of the alternating copolymer of butadiene and propene using classical metathesis catalysts can produce non-polymerizable via ring-opening metathesis polymerization 4-methylcyclo- 
hexene [17]. The effect of dichloromethane and hexane solvents on the metathesis degradation of polyalkenamers in block copolymers has been reported [22]. It is worth noting that the cross-metathesis degradation of block copolymers containing polybutadiene and polyisoprene units has been less studied [22].

The goal of this study is the cross-metathesis degradation of polybutadiene in block copolymers in the presence citrus oils as chain transfer agents (CTAs) and green solvents using commercially accessible Ru-alkylidene catalysts $\left(\mathrm{PCy}_{3}\right)_{2}(\mathrm{Cl})_{2} \mathrm{Ru}=\mathrm{CHPh}(\mathrm{I})$ and (1,3-diphenyl4,5-dihydroimidazol-2-ylidene) $\left(\mathrm{PCy}_{3}\right) \mathrm{Cl}_{2} \mathrm{Ru}=\mathrm{CHPh}(\mathbf{I I})$.

\section{EXPERIMENTAL}

\subsection{Reagents}

Mandarin, lemon and orange oils were obtained from Natural Oils \& Chemical and used without purification. Poly(styrene-co-butadiene) (styrene, $30 \mathrm{wt} \%)\left(M_{n}=1.70\right.$ $\left.\times 10^{5}, \mathrm{MWD}=1.5, \mathrm{SB}-1\right)$ and poly(styrene-co-butadiene $)$ (styrene, $21 \mathrm{wt} \%)\left(M_{n}=1.92 \times 10^{5}, \mathrm{MWD}=1.4\right.$, SB-2); $d$-limonene (Aldrich, $\geq 97 \%) ;\left(\mathrm{PCy}_{3}\right)_{2}(\mathrm{Cl})_{2} \mathrm{Ru}=\mathrm{CHPh}$ (first generation Grubbs catalyst) (I) and (1,3-diphenyl4,5-dihydroimidazol-2-ylidene) $\left(\mathrm{PCy}_{3}\right) \mathrm{Cl}_{2} \mathrm{Ru}=\mathrm{CHPh}($ second generation Grubbs catalyst) (II); methanol, hexane and chlorobenzene anhydrous solvents were purchased from Aldrich Chemical Co. and used as received. 1,2dichloroethane was dried over calcium hydride $\left(\mathrm{CaH}_{2}\right)$ and distilled.

\subsection{Techniques}

${ }^{1} \mathrm{H}-\mathrm{NMR}$ and ${ }^{13} \mathrm{C}-\mathrm{NMR}$ spectra were recorded on a Varian spectrometer Inova Unit 300 model at 300 and 75 $\mathrm{MHz}$, respectively in $\mathrm{CDCl}_{3}$. Tetramethylsilane (TMS) was used as internal standards. FT-IR spectra were obtained on a Nicolet 5700 using a diamond tip as dispersing agent. Number-average molecular weight $\left(M_{n}\right)$ and molecular weight distributions (MWD) were determined with reference to monodisperse polystyrene standards on a waters 2695 ALLIANCE Separation Module GPC at $30^{\circ} \mathrm{C}$ in tetrahydrofuran (THF) using a universal column and a flow rate of $0.3 \mathrm{ml} / \mathrm{min}$.

GC-MS (EI) chromatograms were recorded using a GC-2010/MS-QP2010s system equipped with an AOC$20 \mathrm{i}$ autosampler, with the injector temperature of $335^{\circ} \mathrm{C}$, at 1:5 split ratio and injection volume of $1 \mathrm{~mL}$. Capillary column separation was used a $0.25 \mathrm{~mL}$ thick film $[30 \mathrm{~m}$ $\times 0.32 \mathrm{mmID}$ Rtx-5MS (RESTEK) with a $5 \mathrm{~m}$ integraguard column] a flow rate of $1.22 \mathrm{ml} / \mathrm{min}$ and $68 \mathrm{kPa}$ helium press, using helium as carrier gas. The column initial temperature is the $45^{\circ} \mathrm{C}$, isothermal for $3 \mathrm{~min}$ then heated at a rate $10^{\circ} \mathrm{C} / \mathrm{min}$ to $150^{\circ} \mathrm{C}$, ramp at $15^{\circ} \mathrm{C} / \mathrm{min}$ to $340^{\circ} \mathrm{C}$, and isothermal for $14 \mathrm{~min}$. The interface and ion source were set at $340^{\circ} \mathrm{C}$ and $220^{\circ} \mathrm{C}$, respectively. The chromatograms were acquired in the electron impact (EI) scan mode at $70 \mathrm{eV}$ with a mass range of $40-600(\mathrm{~m} / \mathrm{z})$ at rate of $0.1 \mathrm{scan} \cdot \mathrm{s}^{-1}$. The data were acquire and processed using Shimadzu GCMS solutions software.

\subsection{Procedure for the Metathesis Degradation of SB-1 and SB-2}

Metathesis degradation of SB-1 and SB-2 copolymers (2 g, $37 \mathrm{mmol}$ ) using $d$-limonene (Scheme 1) and mandarin, lemon and orange oils as CTAs was carried out under nitrogen atmosphere, in a glass vial, with a temperature of $50^{\circ} \mathrm{C}$. The catalyst $\left(\mathrm{PCy}_{3}\right)_{2}(\mathrm{Cl})_{2} \mathrm{Ru}=\mathrm{CHPh}(\mathbf{I})$ or (1,3-diphenyl-4,5-dihydroimidazol-2-ylidene) $\left(\mathrm{PCy}_{3}\right)$ $\mathrm{Cl}_{2} \mathrm{Ru}=\mathrm{CHPh}(\mathbf{I I})$ was added in molar ratio $[\mathrm{C}=\mathrm{C}] /$ catalyst $=1000$. The reactions were carried out in bulk (solvent was added only with the catalysts) or using essential oils, 1,2-dicloroethane and dichlorobenzene as solvents (initial copolymer concentration $\left[\mathrm{M}_{\mathrm{o}}\right]=1 \mathrm{~mol} / \mathrm{L}$ ). Essential oils and $d$-limonene (CTAs) were used in several molar ratios of NR to CTA $[\mathrm{C}=\mathrm{C}] /[\mathrm{CTA}]=1: 1,5: 1$ and 10:1. After terminating the reaction by addition of a small amount of ethyl vinyl ether, the solution was poured into an excess of methanol. The polystyrene blocks could be isolated in hexane. The products were dried under vacuum and characterized by ${ }^{1} \mathrm{H},{ }^{13} \mathrm{C}-\mathrm{NMR}$, FT-IR, GPC, SEC and GC/MS (EI). Isolated yields of butadiene oligomers were high and ranged between $91 \%$ - 95\%.
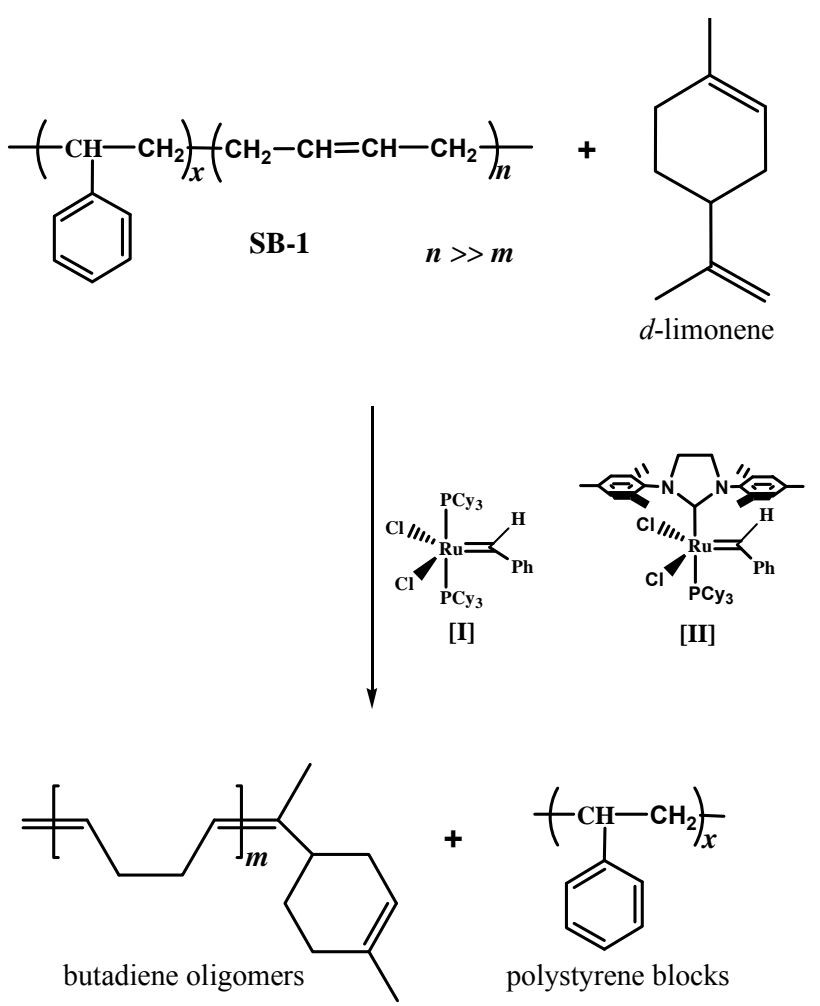

Scheme 1. Cross-metathesis of poly(styrene-co-butadiene) (styrene, $30 \mathrm{wt} \%$ ) (SB-1) with $d$-limonene. 
${ }^{1} \mathrm{H}-\mathrm{NMR}\left(300 \mathrm{MHz}, \mathrm{CDCl}_{3}, \mathrm{ppm}\right) . \delta 5.65$ (br, $\mathrm{CH}=\mathrm{C}$ cyclic terpene); $\delta 5.41$ (s, $\mathrm{CH}=\mathrm{C}$ butadiene); $\delta 5.09$ $4.92\left(\mathrm{~m}, \mathrm{CH}_{2}=\mathrm{C}\right.$ terpene); $\delta 2.03,0.88-0.82\left(\mathrm{~m}, \mathrm{CH}_{2}\right.$ butadiene); $\delta 1.26\left(\mathrm{~s}, \mathrm{CH}_{3}\right) ; \delta 7.09-6.37$ (m, $\mathrm{CH}$ styrene aromatic); $\delta 1.87-1.84\left(\mathrm{~m}, \mathrm{CH}_{2}\right) ; \delta 1.54-1.24(\mathrm{~m}, \mathrm{CH}$ styrene).

${ }^{13} \mathrm{C}-\mathrm{NMR}\left(75 \mathrm{MHz}, \mathrm{CDCl}_{3}, \mathrm{ppm}\right) . \delta 133.5$ (s, $\mathrm{C}=\mathrm{C}$ butadiene); $\delta 132.6,130.7$ (s, $\mathrm{C}=\mathrm{C}$ terpene); $\delta 130.0$, 129.3 and $128.8(\mathrm{~s}, \mathrm{CH}=\mathrm{CH}$ butadiene); $\delta 118.5(\mathrm{~s}, \mathrm{CH}$ $=\mathrm{C}$ cyclic terpene); $\delta 114.6\left(\mathrm{~s}, \mathrm{CH}_{2}=\mathrm{C}\right.$ vinylic); $\delta 39.2$ (s, $\mathrm{CH}$ terpene); $\delta 34.5$ and 32.8 (s, $\mathrm{CH}_{2}$ terpene); 29.1 (s, $\mathrm{CH}_{2}$ butadiene); $\delta 22.8,14.2$ (s, $\mathrm{CH}_{3}$ aliphatic terpene); $\delta$ $145.3,130.0-129.4,128.0,125.6(\mathrm{~m},=\mathrm{C}-\mathrm{H}$ styrene aromatic); $\delta 40.5$ (s, CH styrene); $\delta 32.7$ (s, $\mathrm{CH}_{2}$ styrene).

FT-IR $\left(v, \mathrm{~cm}^{-1}\right)$. Butadiene oligomers: $2921\left(v_{\text {as }} \mathrm{C}-\mathrm{H}\right.$, $\mathrm{CH}_{2}$, str); $2851\left(v_{\mathrm{s}} \mathrm{C}-\mathrm{H}, \mathrm{CH}_{2}\right.$, str); $1658\left(\mathrm{C}=\mathrm{CH}_{2}\right.$, str).

Polystyrene blocks: 3024 ( $\mathrm{CH}$ aromatics, str); 2922 ( vas $\mathrm{C}-\mathrm{H}, \mathrm{CH}_{2}$, str); 2825(v $v_{s} \mathrm{C}-\mathrm{H}, \mathrm{CH}_{2}$, str); $1600(\mathrm{C}=\mathrm{C}$, str).

GC/MS (EI) min (Component, m/z, abundance): 14.98
$\left(\mathbf{A}_{m}=1,190,43 \%\right), 28.64\left(\mathbf{A}_{m}=2,244,2 \%\right), 11.48\left(\mathbf{A}_{m}\right.$ $=3,298,6 \%), 13.81\left(\mathbf{A}_{m}=4,352,1 \%\right), 7.58\left(\mathbf{B}_{m}=2\right.$, $136,13 \%), 18.06\left(\mathbf{B}_{m}=3,190,10 \%\right), 18.24\left(\mathbf{C}_{m}=1,298\right.$, 15\%), 12.72 (trimer, 162, 10\%).

\section{RESULTS AND DISCUSSION}

The major constituent of citrus oils is $d$-limonene with $74 \%$ for mandarin, $87 \%$ for lemon and $97 \%$ for orange oils. Table 1 presents the composition of used citrus oils according to GS/MS (EI) analysis. The citrus oils were used as chain transfer agents (CTAs) and green solvents in the cross-metathesis degradation of poly (styrene-cobutadiene) (styrene, $30 \mathrm{wt} \%$ ) (SB-1) and poly (styreneco-butadiene) (styrene, $21 \mathrm{wt} \%$ ) (SB-2). The copolymers contain more than $96 \%$ of trans-1,4-butadiene units. The Scheme 1 depicts the cross-metathesis of SB-1 with $d$ limonene.

Table 2 summarizes the results of SB-1 and SB-2 degradation via cross-metathesis with citrus oils and $d$ limonene by catalysts I and II.

Table 1. Composition of mandarin, lemon and orange oils determined by GC/MS (EI).

\begin{tabular}{ccccc}
\hline \multicolumn{1}{c}{} & \multicolumn{3}{c}{ Composition \% } \\
\hline No. & Compounds & Mandarin oil & lemon oil & Orange oil \\
\hline 1 & $d$-limonene & $\mathbf{7 4 . 0}$ & $\mathbf{8 7 . 0}$ & $\mathbf{9 7 . 0}$ \\
2 & $\beta$-myrcene & 1.3 & 3.1 & 1.5 \\
3 & $\beta$-pinene & 3.0 & 3.7 & \\
4 & $\alpha$-pinene & 4.2 & & \\
5 & $\gamma$-terpinene & 15.6 & & \\
6 & $p$-cymene & 0.6 & & \\
7 & Dimethyl anthranilate & 0.5 & & \\
8 & Geraniol acetate, citronellol & 0.8 & 1.1 & \\
9 & Terpinolene & & 1.7 & \\
10 & $1,3,7$-octatriene & & 2.1 & \\
11 & Citral & &
\end{tabular}

Table 2. Degradation of SB-1 and SB-2 with essential oils and $d$-limonene using catalyst $\mathbf{I}$ and II (degradation was in bulk using molar ratio: $[\mathrm{C}=\mathrm{C}] /[$ Catalyst $]=1000$ and $\left.\mathrm{T}=50^{\circ} \mathrm{C}\right)$.

\begin{tabular}{|c|c|c|c|c|c|c|c|c|}
\hline Entry & Rubber & Catalyst & CTA & {$[\mathrm{C}=\mathrm{C}]^{\mathrm{a} /} /[\mathrm{CTA}]$} & Time h & Yield $^{\mathrm{b}}$ (\%) & $M_{n}{ }^{\mathrm{c}}\left({ }^{1} \mathrm{H}-\mathrm{NMR}\right)$ & $\mathrm{M}_{n}^{\mathrm{d}}$ (SEC) \\
\hline \multicolumn{8}{|c|}{$\begin{array}{l}\text { poly(styrene-co-butadiene) (styrene, } 30 \mathrm{wt} \% \text { ) (SB-1) } \\
\text { poly(styrene-co-butadiene) (styrene, } 21 \mathrm{wt} \% \text { ) (SB-2) }\end{array}$} & $\begin{array}{l}1.70 \times 10^{5} \\
1.92 \times 10^{5}\end{array}$ \\
\hline 1 & SB-1 & I & $d$-limonene & $1: 1$ & 1 & 76 & - & 71,629 \\
\hline 2 & SB-1 & I & $d$-limonene & $1: 1$ & 10 & 80 & - & 9400 \\
\hline 3 & SB-1 & I & $d$-limonene & $1: 1$ & 14 & 87 & 1603 & 1532 \\
\hline 4 & SB-1 & I & $d$-limonene & $1: 1$ & 24 & 91 & 270 & 305 \\
\hline 5 & SB-1 & I & Mandarin oil & $1: 1$ & 24 & 91 & 251 & 276 \\
\hline 6 & SB-1 & I & Mandarin oil & $5: 1$ & 24 & 94 & 496 & 512 \\
\hline 7 & SB-1 & I & Mandarin oil & $10: 1$ & 24 & 95 & 687 & 706 \\
\hline 8 & SB-1 & I & Lemon oil & $1: 1$ & 24 & 92 & 290 & 313 \\
\hline 9 & SB-1 & I & Orange oil & $1: 1$ & 24 & 93 & 285 & 325 \\
\hline 10 & SB-1 & II & Mandarin oil & $1: 1$ & 12 & 92 & 276 & 299 \\
\hline 11 & SB-1 & II & Mandarin oil & $5: 1$ & 12 & 93 & 452 & 468 \\
\hline 12 & SB-1 & II & Mandarin oil & 10:1 & 12 & 93 & 681 & 697 \\
\hline 13 & SB-2 & I & Mandarin oil & $1: 1$ & 24 & 95 & 297 & 335 \\
\hline 14 & SB-2 & II & Mandarin oil & $1: 1$ & 12 & 94 & 263 & 287 \\
\hline
\end{tabular}

${ }^{\mathrm{a}}$ Molar ratio of $[\mathrm{C}=\mathrm{C}]$ to CTA; ${ }^{\mathrm{b}}$ Yields of the isolated products; ${ }^{\mathrm{c}} M_{n}$ determined by ${ }^{1} \mathrm{H}-\mathrm{NMR}$, end groups analysis where one unit of terpene is attached to the end-group of the butadiene oligomeric chain; ${ }^{\mathrm{d}}$ Number-average molecular weights $\left(M_{n}\right)$ of the butadiene oligomers were determined by size exclusion chromatography (SEC) in THF with polystyrene calibration standards. $M_{n}$ of the oligomers butadiene (entries $6,7,11,12$ ) and polystyrene blocks were calculated by gel permeation chromatography (GPC) (THF as eluent with polystyrene calibration standards) and SEC. 
It is important to note that the control experiments showed that the monoterpenes of citrus oils in the presence of Ru-alkylidene catalysts did not participate in the isomerization and self-metathesis reactions to produce non-desired products [15].

The evaluation of SB-1 molecular weights with increasing reaction time using $d$-limonene and catalyst $\mathbf{I}$ is represented in Table 2. The rapid decrease of the polymer molecular weight, corresponding to a $M_{n}$ drop from 71,629 to about $9,400 \mathrm{~g} \cdot \mathrm{mol}^{-1}$ is observed.

Kinetics of the cross-metathesis degradation indicates that the butadiene oligomers are mainly formed during the first $10 \mathrm{~h}$. Then, in the second stage, from about 14 to $24 \mathrm{~h}$, copolymer molecular weights slowly decreased to finally reach the butadiene products with a molecular weight of about $305 \mathrm{~g} \cdot \mathrm{mol}^{-1}$.

As observed, both catalysts I and II showed high efficiency to produce the similar low molecular weight products (Table 2).

It is worth noting, that the first generation Ru-alkylidene catalyst I exhibited poor efficiency in the crossmetathesis degradation of natural rubber with $d$-limonene, when the second generation catalyst II in the same conditions allowed the formation of isoprene oligomers with controlled molecular weights [15]. These results are a real confirmation of the fact that the activation energy of metathesis of challenging olefins, especially trisubsti- tuted internal olefins by the first generation Grubbs catalyst is higher than that of the second generation one [24]. Thus, the experimental and computational studies revealed that the $N$-heterocyclic carbene containing $\mathrm{Ru}$ alkylidenes are the best catalysts for challenging substrats. [20,24,25]. After the cross-metathesis degradation butadiene oligomers with yields ranging from 91\% $95 \%$ and values around $M_{n}=276-335 \mathrm{~g} \cdot \mathrm{mol}^{-1}$ (entries 4, $5,8-10,13$ and 14), and polystyrene blocks with values around $M_{n}=13-15 \times 10^{4} \mathrm{~g} \cdot \mathrm{mol}^{-1}$ were isolated.

Figure 1 showed ${ }^{1} \mathrm{H}-\mathrm{NMR}$ spectra of SB-1 before (a) and after (b), (c) the degradation via cross-metathesis with mandarin oil (Table 2, entry 5). The spectrum (b) corresponded to the liquid fraction of butadiene oligomers. The signals arising in the 5.09 - 4.92 ppm region were assigned to the protons of a vinyl group, while the signal observed at $5.65 \mathrm{ppm}$ was attributed to the protons of the double bond in the terpene cycle. The signals of the aliphatic protons of $d$-limonene are observed at 0.88 $0.82 \mathrm{ppm}$. The signals in the spectrum (c) at $7.09-6.37$ ppm corresponded to the aromatic protons, while the signals arising in the $1.84-1.87$ and $1.54-1.24$ ppm regions were attributed to protons of $\mathrm{CH}_{2}$ and $\mathrm{CH}$ groups in the polystyrene units [26].

The experimental molecular weights of butadiene oligomers determined by GPC, SEC and end-group analysis using ${ }^{1} \mathrm{H}-\mathrm{NMR}$ spectroscopy (Table 2) were slightly

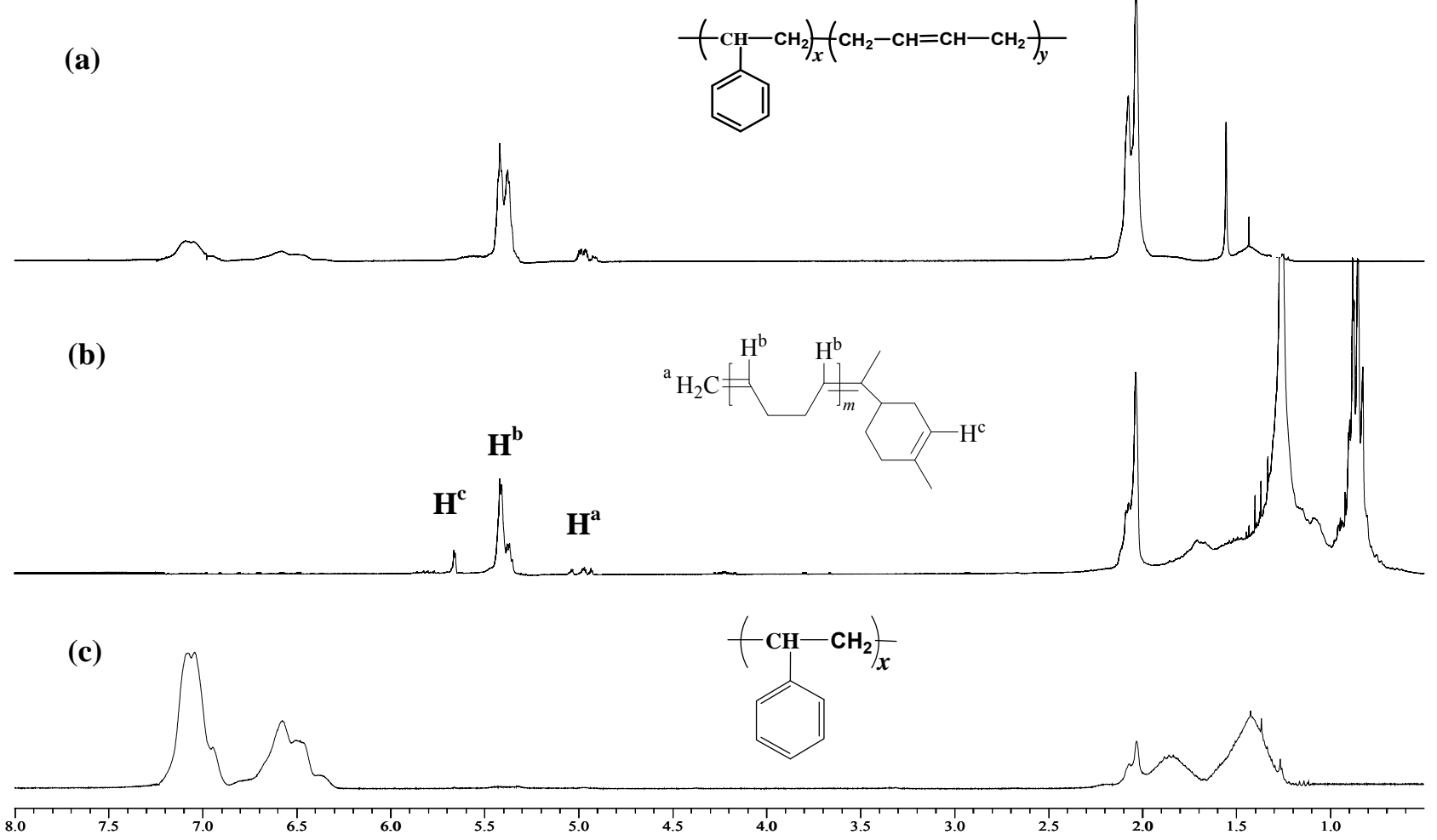

Figure 1. ${ }^{1} \mathrm{H}-\mathrm{NMR}\left(300 \mathrm{MHz}, \mathrm{CDCl}_{3}\right.$ ) spectra of SB-1 before (a) and after (butadiene oligomers (b) and polystyrene blocks (c) the cross-metathesis degradation with mandarin oil. 
higher than the theoretical molecular weights. This phenomenon could be explained by the intramolecular cyclizations reactions of polymer chains and acyclic diene metathesis polymerization obtained during the crossmetathesis of methylene terminated products [14].

The molecular weight of products may be controlled by changing the ratio CTAs to butadiene units (Table 2, entries 5 - 7 and 10 - 12). Figure 2 shows GPC chromatogram of products obtained via cross-metathesis degradation of SB-1 in the presence of mandarin oil ( $[\mathrm{C}=\mathrm{C}] /$ $[\mathrm{CTA}]=10: 1$ molar ratio) (Table 2, entry 7).

The cross-metathesis degradation of copolymers was also investigated using citrus oils as green solvents. Table 3 demonstrated the results of cross-metathesis degradation of SB-1 by catalyst $\mathbf{I}$ using mandarin, lemon and orange oils, 1,2-dichloroethane and chlorobenzene as solvents. It is seen that the copolymer degradation in organic solvents and in mandarin, lemon and orange oils proceeded with similar efficiency and resulted in the same molecular weight butadiene oligomers. Scheme 2 shows the composition and yields of butadiene oligomers according to GS/MS (EI) analysis (Table 2, entry 4). As seen from Scheme 2 the products of this reaction were $\mathbf{A}_{\boldsymbol{m}}(52 \%), \mathbf{B}_{\boldsymbol{m}}(23 \%)$, and $\mathbf{C}_{\boldsymbol{m}}(15 \%)$. Figure 3 presents the mass-spectrum of the major product $\mathbf{A}_{\boldsymbol{m}}$ with $\boldsymbol{m}=1$ $(\mathrm{m} / \mathrm{z}=190,43 \%)$. Interestingly, that in the case of natural rubber cross-metathesis with $d$-limonene the formation of oligomers with terpene terminated groups in both side (series $\mathbf{C}_{\boldsymbol{m}}$ ) did not detected [15]. These results point out that the metathesis reaction, in particular the crossmetathesis degradation of natural rubber in the presence of $d$-limonene as a CTA proceeded via the formation of less substituted intermediate in a transition state.

Computational modeling of natural rubber metathesis

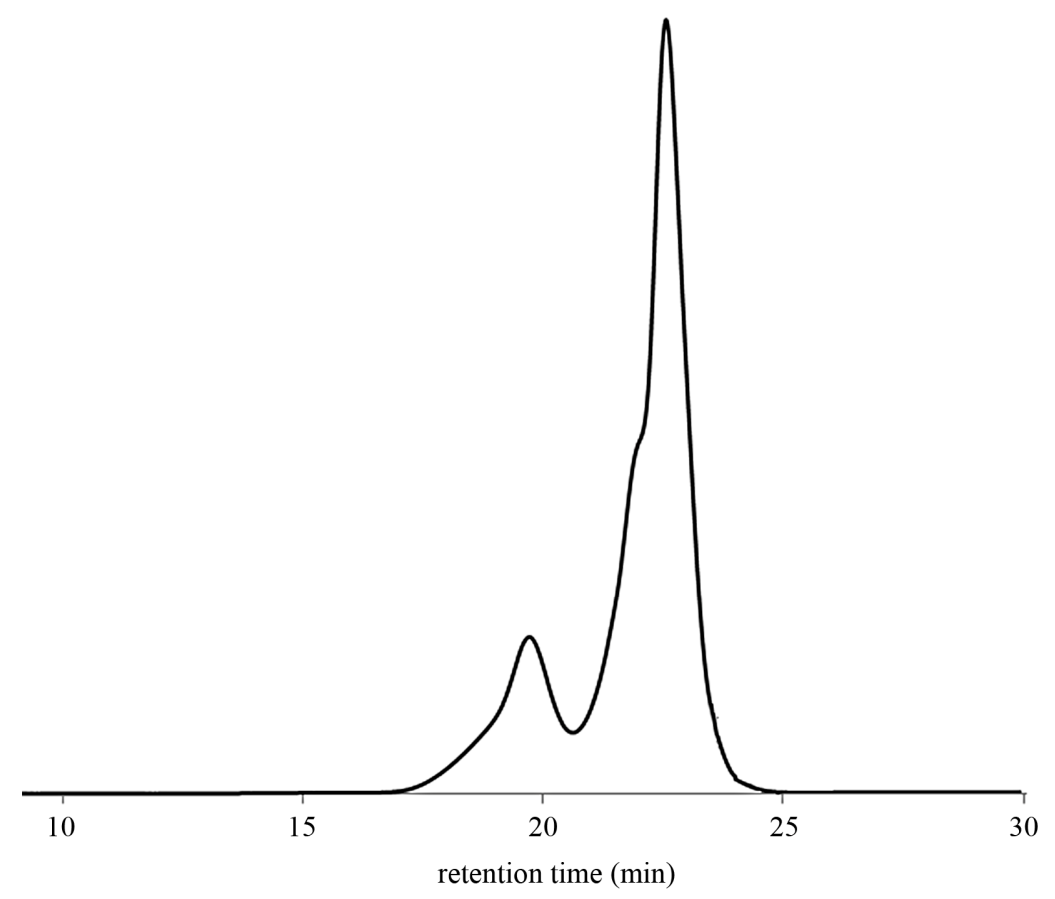

Figure 2. GPC chromatogram of products after the degradation of SB-1 in the presence of mandarin oil $([\mathrm{C}=\mathrm{C}] /[\mathrm{CTA}]=10: 1$ molar ratio $)$.

Table 3. Degradation of SB-1 using essential oils, 1,2-dichloroethane and chlorobenzene as solvents. $\{[\mathrm{C}=\mathrm{C}] /[\mathbf{I}]=1000 \mathrm{molar}$ ratio, $\mathrm{T}=50^{\circ} \mathrm{C}$ and $\left.\mathrm{t}=24 \mathrm{hrs}\right\}$.

\begin{tabular}{|c|c|c|c|c|c|}
\hline Entry & Solvent $^{\mathrm{a}}$ & {$[\mathrm{C}=\mathrm{C}]^{\mathrm{b}} /[\mathrm{CTA}]$} & Yield $\%$ & $\mathrm{M}_{n}{ }^{\mathrm{d}}\left({ }^{1} \mathrm{H}-\mathrm{NMR}\right)$ & $\mathrm{M}_{n}^{\mathrm{e}}$ (SEC) \\
\hline \multicolumn{3}{|c|}{ poly(styrene-co-butadiene) (styrene, 30 wt\%) (SB-1) } & & $1.7 \times 10^{5}$ & \\
\hline 1 & 1,2-dichloroethane & $1: 1$ & 95 & 295 & 330 \\
\hline 2 & Chlorobenzene & $1: 1$ & 94 & 303 & 345 \\
\hline 3 & Mandarin oil & - & 94 & 281 & 309 \\
\hline 4 & Lemon oil & - & 93 & 284 & 317 \\
\hline 5 & Orange oil & - & 94 & 293 & 324 \\
\hline
\end{tabular}

${ }^{\mathrm{a}}$ Initial SB-1 concentration $\left[\mathrm{M}_{\mathrm{o}}\right]=1 \mathrm{~mol} / \mathrm{L} ;{ }^{\mathrm{b}}$ Molar ratio of $[\mathrm{C}=\mathrm{C}]$ to mandarin oil as CTA; ${ }^{\mathrm{c}}$ Yields of the butadiene oligomers; ${ }^{\mathrm{d}} M_{n}$ determined by ${ }^{1} \mathrm{H}-\mathrm{NMR}$, end groups analysis where one unit of $d$-limonene contained in the essential oils is attached to the end-group of the butadiene oligomeric chain; ${ }^{\mathrm{e}} \mathrm{Num}$ ber-average molecular weights $\left(M_{n}\right)$ of the butadiene oligomers were determined by size exclusion chromatography (SEC) in THF with polystyrene calibration standards. $M_{n}$ of polystyrene blocks were calculated by gel permeation chromatography (GPC) (THF as eluent with polystyrene calibration standards) and SEC. 


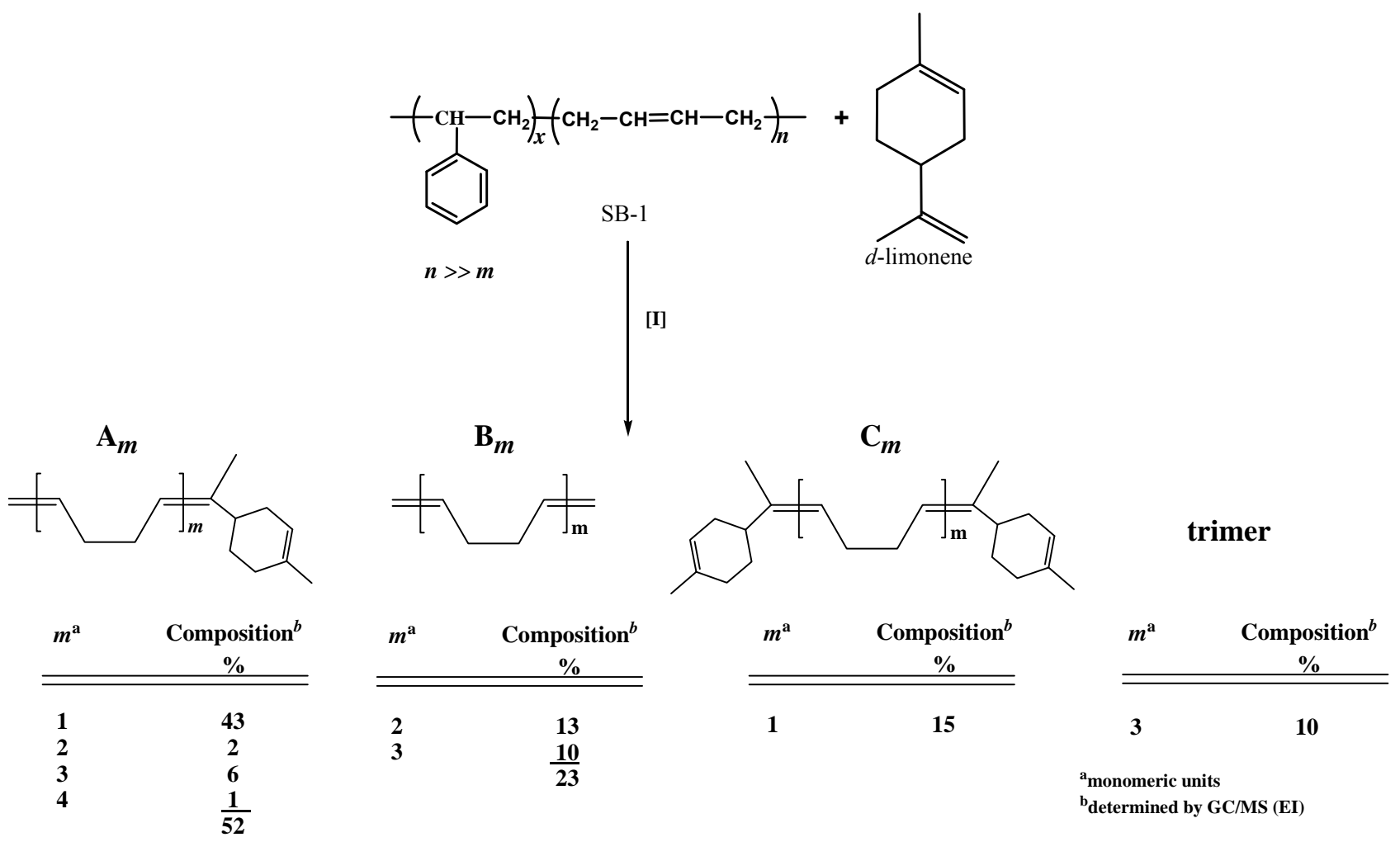

Scheme 2. Composition and yields of butadiene oligomers obtained during the cross-metathesis of SB-1 with $d$-limonene.

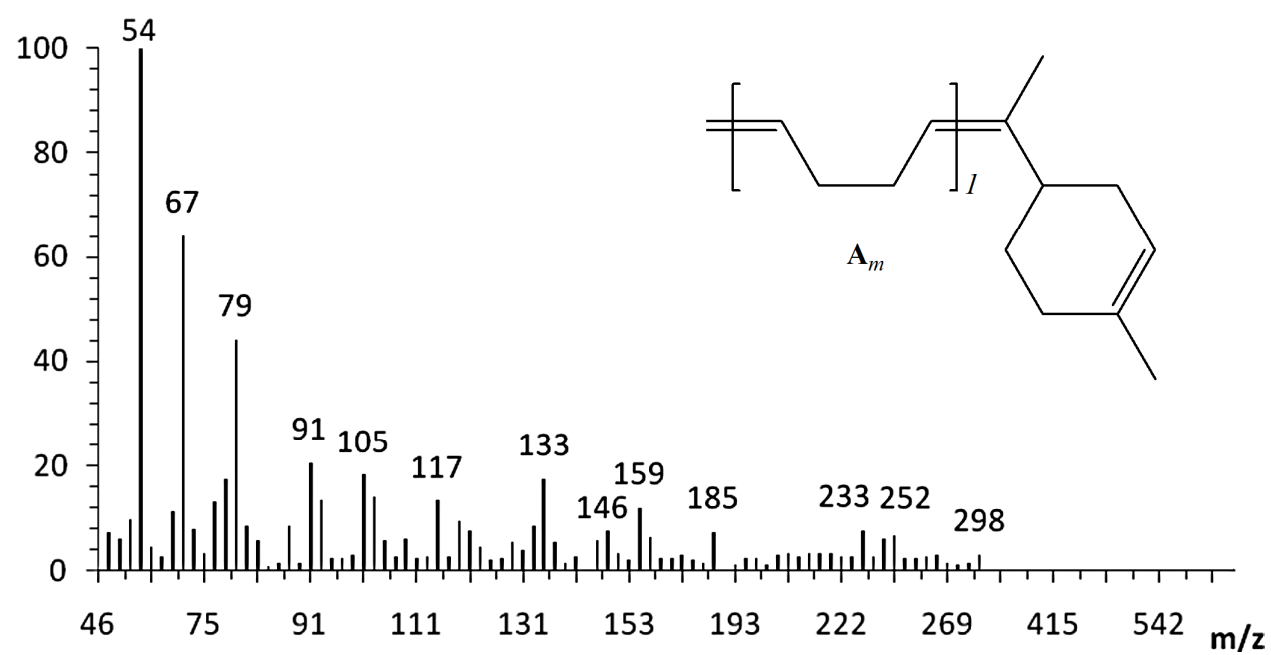

Figure 3. The mass spectrum of the $\mathbf{A}_{m}$ product with $m=1\left(\mathrm{C}_{14} \mathrm{H}_{22}, \mathrm{~m} / \mathrm{z}=190,43 \%\right)$.

using the first (I) and second (II) generation Ru-alkylidene catalysts revealed that the highly substituted metalcyclobutane intermediate will show the elevated activation energy compared to unsubstituted or less substituted intermediates [24]. The cross-metathesis degradation of copolymers is accompanied by the intramolecular cyclization reactions of butadiene units to form the cyclic trimers trans,trans,trans-1,5,9-cyclododecatriene as the most thermodynamically favored among the all cyclic and linear products $[27,28]$ (Scheme 2).

\section{CONCLUSION}

The cross-metathesis degradation of polybutadiene in block copolymers in the presence citrus oils and $d$-limonene as chain transfer agents (CTAs) using I and II catalysts was described. Catalysts I and II showed high efficiency in the cross-metathesis SB-1 and SB-2 copolymers providing the formation of limonene terminated butadiene oligomers with the low molecular weight values around $M_{n}=276-335 \mathrm{~g} \cdot \mathrm{mol}^{-1}$ and yielded ranging from $91 \%-95 \%$. The cross-metathesis degradation 
of copolymers using organic solvents and citrus oils proceeded with similar efficiency and resulted in the same molecular weight butadiene oligomers. The limoneneterminated butadiene oligomers of the series $\mathrm{A}_{m}$ with $m=$ 1 unit were the major product $(43 \%)$ in the degradation of SB-1.

\section{ACKNOWLEDGEMENTS}

We thank CONACyT-SEMARNAT (contract 23432) for generous support to this research. We are grateful to Alejandrina Acosta, Salvador López Morales and Miguel Ángel Canseco Martínez for their assistance in NMR, GPC, SEC, GC-MS and IR.

\section{REFERENCES}

[1] Baser, K.H.C. and Buchbauer, G. (2010) Handbook of essential oils: Science, technology and applications. CRC Press, Boca Raton/London/New York.

[2] Puskas, J.E. and Kaszas, G., (2003) Carbocationic polymerization. Encyclopedia of polymer science and technology, V5, Wiley-Interscience, New York.

[3] Kennedy, J.P. (1975) Cationic polymerization of olefins: A critical inventory. Wiley-Interscience, New York.

[4] Vougioukalakis, G.C. and Grubbs, R.H. (2008) Synthesis and activity of ruthenium olefin metathesis catalysts coordinated with thiazol-2-ylidene ligands. Journal of the American Chemical Society, 130, 2234-2245. doi:10.1021/ja075849v

[5] Sashuk, V., Peeck, L.H. and Plenio, H. (2010) $\left[(\mathrm{NHC})\left(\mathrm{NHC}_{\text {ewg }}\right) \mathrm{RuCl}_{2}(\mathrm{CHPh})\right]$ complexes with modified $\mathrm{NHC}_{\text {ewg }}$ ligands for efficient ring-closing metathesis leading to tetrasubstituted olefins. Chemical European Journal, 16, 3983-3993. doi:10.1002/chem.200903275

[6] Meek, S.J., O’Brien, R.V., Llaveria, J., Schrock, R.R. and Hoveyda, A.H. (2011) Catalytic Z-selective olefin crossmetathesis for natural product synthesis. Nature, 471, 461466. doi:10.1038/nature09957

[7] Fomine, S. and Tlenkopatchev, M.A. (2012) Metathesis transformations of terpenes. Computational modeling of (-)- $\alpha$-pinene ring opening by ruthenium and tungsten carbene catalysts, Journal Organometallic Chemistry, 701, 68-74. doi:10.1016/j.jorganchem.2011.12.023

[8] Srikrishna, A., Dethe, D.H. and Kumar, P.R. (2004) Enantiospecific construction of the BC-ring system of taxanes. Tetrahedron Letters, 45, 2939-2942. doi:10.1016/j.tetlet.2004.02.075

[9] Mehta, G. and Kumaran, R.S. (2005) A sequential RCM/ fragmentation protocol towards chiral, stereodefined medium ring sesquiterpenoids. A carvone route to E- and Z-germacrenes. Tetrahedron Letters, 46, 8831-8835. doi:10.1016/j.tetlet.2005.10.093

[10] Bilel, H., Hamdi, N., Zagrouba, F., Fischmeister, C. and Bruneau, C. (2011) Cross-metathesis transformations of terpenoids in dialkyl carbonate solvents. Green Chemistry, 13, 1448-1452. doi:10.1039/c1gc15024c

[11] Mathers, R.T., McMahon, K.C., Damodaran, K., Retaride,
C.J. and Kelly, D.J. (2006) Ring-opening metathesis polymerizations in D-limonene: A renewable polymerizetion solvent and chain transfer agent for the synthesis of alkene macromonomers. Macromolecules, 39, 8982-8986. doi: $10.1021 / \mathrm{ma} 061699 \mathrm{~h}$

[12] Mathers, R.T., Damodaran, K., Rendos, M.G. and Lavrich, M.S. (2009) Functional hyperbranched polymers using ring-opening metathesis polymerization of dicyclopentadiene with monoterpenes. Macromolecules, 42, 15121518. doi: $10.1021 / \mathrm{ma} 802441 \mathrm{t}$

[13] Justin, M.D., Matthew, D.C, Matthew, G.R, Cory, J.U., Susan, G.P. and Mathers, R.T. (2011) Controlling crosslinking in thermosets via chain transfer with monoterpenes. Journal of Polymer Science Part A: Polymer Chemistry, 49, 3719-3727. doi:10.1002/pola.24808

[14] Gutierrez, S. and Tlenkopatchev, M.A. (2011) Metathesis of renewable products: Degradation of natural rubber via cross-metathesis with $\beta$-pinene using Ru-alkylidene catalysts. Polymer Bulletin, 66, 1029-1038. doi:10.1007/s00289-010-0330-x

[15] Martinez, A., Gutierrez, S. and Tlenkopatchev, M.A. (2012) Metathesis transformations of natural products: Cross-metathesis of natural rubber and mandarin oil by Ru-alkylidene catalysts. Molecules, 17, 6001-6010. doi:10.3390/molecules17056001

[16] Ivin, K.J. and Mol, J.C. (1997) Olefin metathesis and metathesis polymerization. Academic Press, California.

[17] Korshak, Yu. V., Dolgoplosk, B.A. and Tlenkopachev, M.A. (1977) Cyclodegradation of polyalkenamers in solutions acted on by disproportionation catalysts. Recueil des Travaux Chimiques des Pays-Bas, 96, M64-M66.

[18] Korshak, Yu. V., Tlenkopatchev, M.A., Dolgoplosk, B.A., Avdeikina, E.G. and Kutepov, D.F. (1982) Intra- and intermolecular metathesis reactions in the formation and degradation of unsaturated polymers. Journal of Molecular Catalysis, 15, 207-218. doi:10.1016/0304-5102(82)80018-7

[19] Thorn-Csanyi, E. (1994) Quantitative metathetic degradation of rubbers and sulfur crosslinked rubbers-Including tires. Rubber Chemistry and Technology, 67, 786-796. doi: $10.5254 / 1.3538710$

[20] Craig, S.W., Monzer, J.A. and Coughlin, E.B. (2001) Highly efficient acyclic diene metastasis depolymerization using a ruthenium catalyst containing a N-heterocyclic carbene ligand. Macromolecules, 34, 7929-7931. doi: $10.1021 / \mathrm{ma} 011188 \mathrm{p}$

[21] Lucas, F., Peruch, F., Carlotti, S., Deffieux, A., Leblanc, A. and Boisson, C. (2008) Synthesis of dihydroxy poly (ethylene-co-butadiene) via metathetical depolymerization: Kinetic and mechanistic aspects. Polymer, 49, 49354941. doi:10.1016/j.polymer.2008.09.012

[22] Sedransk, K.L., Kaminski, C.F., Hutchings, L.R. and Moggridge, G.D. (2011) The metathetic degradation of polyisoprene and polybutadiene in block copolymers using Grubbs second generation catalyst. Polymer Degradation and Stability, 96, 1074-1080. doi:10.1016/j.polymdegradstab.2011.03.007

[23] Sadaka, F., Compistron, I., Laguerre, A. and Pilard, J. (2013) The metathetic degradation of polyisoprene and 
polybutadiene in block copolymers using Grubbs second generation catalyst. Polymer Degradation and Stability, 98, 736-742. doi:10.1016/j.polymdegradstab.2012.12.018

[24] Fomine, S. and Tlenkopatchev, M.A. (2010) Computational modeling of renewable molecules. Ruthenium alkylidene-mediated metathesis of trialkyl-substituted olefins. Organometallics, 29, 1580-1587. doi:10.1021/om900848q

[25] Fomine, S. and Tlenkopatchev, M.A. (2007) Ring-opening of cyclohexene via metathesis by ruthenium carbene complexes. A computational study. Organometallics, 26, 4491-4497. doi:10.1021/om700425d

[26] Bevington, J.C. and Huckerby, T.N. (2006) Studies of end-groups in polystyrene using ${ }^{1} \mathrm{H}-\mathrm{NMR}$. European Poly- mer Journal, 42, 1433-1436. doi:10.1016/j.eurpolymj.2005.12.011

[27] Tlenkopatchev, M.A., Barcenas, A. and Fomine, S. (2001) Computational study of metathesis degradation of rubber, 2. Distribution of cyclic oligomers via intramolecular metathesis. Degradation of Natural Rubber, Macromolecular Theory and Simulations, 10, 441-446. doi:10.1002/1521-3919(20010601)10:5<441::AID-MATS 441>3.0.CO;2-\#

[28] Thorn-Csanyi, E., Hummer, J. and Zilles, J.U. (1994) Metathetic ring-chain equilibrium; synthesis of 1,5,9-trimethyl-(1E,5E,9E)-cyclododecatriene from 1,4-polyisoprene. Macromolecular Rapid Communications, 15, 797-800. doi:10.1002/marc.1994.030151008 